\title{
Urinary proteomic pattern in female stress urinary incontinence: a pilot study
}

\author{
Marianne Koch $^{1}$ - Goran Mitulovic ${ }^{2}$ - Engelbert Hanzal ${ }^{1}$ - Wolfgang Umek ${ }^{1}$. \\ Sonja Seyfert ${ }^{2} \cdot$ Thomas Mohr $^{3} \cdot$ Heinz Koelbl $^{1} \cdot$ Rosa Maria Laterza $^{1}$
}

Received: 17 December 2015 / Accepted: 19 April 2016/Published online: 18 May 2016

(C) The Author(s) 2016. This article is published with open access at Springerlink.com

\begin{abstract}
Introduction and hypothesis Previous studies aiming to identify specific pre-defined urine protein biomarkers for stress urinary incontinence (SUI) have not identified clinically important differences. The hypothesis of our study was that the global distribution of urinary proteins, the proteome, differs between women with and those without SUI.

Methods In this age-matched case-control study, we compared the urinary proteome of 20 women with SUI and 20 controls. Proteins were identified by applying highperformance liquid chromatography separation and tandem mass spectrometry detection. Data analysis was performed using Mascot 2.4.1 embedded in ProteinScape 3.1.

Results We identified 828 different proteins. The concentration of six of those showed a significant difference between urine samples of SUI patients and those of controls ( $q$ value $<0.25$ ). Four proteins showed a higher abundance in SUI
\end{abstract}

This study was presented as an oral poster presentation at the 45th Annual Meeting of the International Continence Society, Montreal, Canada, 6-9 October 2015

Electronic supplementary material The online version of this article (doi:10.1007/s00192-016-3033-5) contains supplementary material, which is available to authorized users

Rosa Maria Laterza

suiproteomics@gmail.com

1 Clinical Division of General Gynecology and Gynecological Oncology, Department of Obstetrics and Gynecology, Medical University of Vienna, Spitalgasse 23, 1090 Vienna, Austria

2 Core Facility Proteomics, Clinical Institute of Laboratory Medicine, Medical University of Vienna, Spitalgasse 23, 1090 Vienna, Austria

3 Science Consult Thomas Mohr KG, Guntramsdorf, Austria samples compared with controls: plasma serine protease inhibitor ( $\log \mathrm{FC} 1.11)$, leucine-rich alpha-2-glycoprotein ( $\log \mathrm{FC} 3.91)$, lysosomal alpha-glucosidase (logFC 1.24), and peptidyl-prolyl cis- trans isomerase A ( $\operatorname{logFC} 1.96)$. We identified two proteins in lower abundance in SUI samples compared with controls: uromodulin $(\log \mathrm{FC}-4.87)$ and TALPID3 ( $\log \mathrm{FC}-1.99)$.

Conclusions Overexpression of plasma serine protease inhibitor, leucine-rich alpha-2-glycoprotein, lysosomal alpha-glucosidase, and peptidyl-prolyl cis- trans isomerase A, and lower expression of uromodulin and TALPID3, in urine may be associated with female SUI.

Keywords Leucine- rich alpha-2-glycoprotein · Lysosomal alpha-glucosidase - Plasma serine protease inhibitor · Uromodulin · TALPID3 · Stress urinary incontinence · Urinary proteome

\section{Introduction}

Stress urinary incontinence (SUI) is defined as the complaint of "involuntary loss of urine on effort or physical exertion including sporting activities, or on sneezing or coughing" [1]. It has a widely varying estimated prevalence of $15-$ $77 \%$ of the female population. SUI represents both a psychological and an economic burden, and prevalence rates are expected to increase in the future, because of increasing life expectancy [2-5]. The classical epidemiology of SUI is well understood, with many environmental and life style risk factors identified, including age, obesity, parity, vaginal delivery, and family history [6-12]. Still, much of the etiology of SUI remains unclear, and it is difficult to predict which women are at risk. 
Proteomics research offers one strategy to elucidate the etiology of SUI by identification of a significant and sufficient number of proteins, which provides the ability to avoid a preselection of candidate proteins. Many different serum, urine, and/or tissue protein markers have been investigated in the context of SUI. Almost all studies have targeted specific proteins as putative biomarkers, but with negative results. Previous studies have investigated the role of serum Creactive protein [13], serum relaxin [14], and serum estradiol [15], without finding significant associations with symptoms.

To our knowledge, no study has yet investigated the complete urinary proteomic profile associated with SUI.

We aimed to determine a possible altered urinary protein profile in women suffering from SUI compared with healthy women, with the overall goal of providing new insights into the pathophysiology.

\section{Materials and methods}

This was a prospective case-control study using proteomic analysis of urine samples from patients with SUI and healthy age-matched controls. Ethics approval was obtained from the ethics committee of the Medical University of Vienna (1788/2013). This trial was registered with ClinicalTrials. gov (NCT02023502).

The study was conducted between October 2013 and June 2015 as a cooperative project among the Department of Obstetrics and Gynecology, the Clinical Division of Urogynecology, and the Proteomics Core Facility, Medical University of Vienna. The inclusion criteria for stress incontinence cases were: a history of symptoms of SUI for at least 3 months (including a specific history of the complaint of involuntary leakage on effort or exertion or on sneezing or coughing), a positive provocation stress test (defined as an observed transurethral loss of urine simultaneous with a cough or Valsalva maneuver at a bladder volume of $300 \mathrm{ml}$ ), negative urine dipstick testing, age $\geq 18$ years, patients capable of independent toileting, written informed consent, and at least one previous vaginal delivery. Exclusion criteria were: previous treatment for SUI (surgical or pharmacological), a history of overactive bladder symptoms and/or urinary incontinence other than SUI (tested using the ICIQ short form questionnaire) [16]; neurological disorders potentially affecting the urinary tract system, such as multiple sclerosis, Parkinson's disease; pelvic organ prolapse stage $\geq$ II (International Continence Society classification), clinically significant bladder outlet obstruction and/or post void residual volume $>100 \mathrm{ml}$; a history of acute urinary retention or a history of repeated catheterizations, a history of bladder cancer or previous surgery to the urinary tract; acute or recurrent urinary tract infection and/or hematuria; a history of urinary tract stones; renal insufficiency and/or hepatic disease; a history of alcohol and/or drug abuse; pregnancy or lactation; and finally any patient with a serious medical condition. Participants in the control group met identical criteria, but with no symptomatic SUI (ICIQ short form score equal to zero), and a negative cough stress test. Urine samples were obtained once only without requirement for a specific time of day. Participants were given a sterile urine cup (maximum $50 \mathrm{ml}$ ) and asked to deliver the first-void urine. In addition, we retrieved blood samples from the peripheral veins of all participants to determine their creatinine, transaminase, and bilirubin status. Urine samples were stored in the refrigerator at $4{ }^{\circ} \mathrm{C}$ for a maximum of $1 \mathrm{~h}$ before being taken to the Clinical Institute of Laboratory Medicine (Proteomics Core Facility) for immediate processing.

Protein precipitation was performed by one of the authors according to the internally modified Wessel-Flüge method of protein precipitation and all solvents were kept at $-20^{\circ} \mathrm{C}$. All working steps were performed on ice and centrifugation in a cooled centrifuge at $+4{ }^{\circ} \mathrm{C}$. Two $\mathrm{ml}$ of each urine sample were mixed with $6 \mathrm{ml}$ methanol and $2 \mathrm{ml}$ dichloromethane in a 50$\mathrm{ml}$ Falcon tube and samples were vigorously vortexed. After adding $6 \mathrm{ml}$ of water to each sample, solutions were vortexed again. Samples were subsequently stored at $-20^{\circ} \mathrm{C}$ for a minimum of $20 \mathrm{~min}$ for enhancement of protein precipitation. Phase separation was carried out by subsequent centrifugation for $5 \mathrm{~min}$ at 4,500 rounds per minute (rpm). The upper layer of the solution was then carefully discarded while keeping the interphase and lower layer, and an additional $6 \mathrm{ml}$ of methanol were added before vigorous vortexing. Final centrifugation was performed for $5 \mathrm{~min}$. The resulting supernatant was carefully removed and the remaining protein pellet was dried in the air. The dried protein pellet was later dissolved in $200 \mu \mathrm{l}$ of $50 \mathrm{mM}$ triethylammonium bicarbonate at $\mathrm{pH} 8.5$ (TEAB). In cases where the protein pellet could not be properly dissolved in $200 \mu \mathrm{l}$ of $50 \mathrm{mM}$ TEAB, an additional $50-1,000 \mu \mathrm{l}$ of $50 \mathrm{mM}$ TEAB were added and the sample was sonicated by using the ultrasonic cell disruptor (Ultrasonic Cell Disruptor; Branson, Dietzenbach, Germany). Bradford protein assay was used to determine the protein concentration within the solution $(\mathrm{mg} / \mathrm{ml})$. The following protein digestion was performed as described by Mitulović et al. [17]. Briefly, disulfide bonds were reduced by the addition of dithiothreitol (DTT; $10 \mu \mathrm{g}$ protein: $0.1 \mu \mathrm{g}$ DTT) and incubation at $56^{\circ} \mathrm{C}$ for $30 \mathrm{~min}$. Alkylation of reduced proteins was performed by the addition of iodacetamide (IAA; $10 \mu \mathrm{g}$ protein: $0.5 \mu \mathrm{g}$ IAA) and incubation in darkness for $20 \mathrm{~min}$ at ambient temperatures. Upon reduction and alkylation, DTT was added to neutralize the excess of IAA and enable tryptic digestion, where sequence grade-modified trypsin (Promega, Mannheim, Germany; $1: 10$ ) was added to the sample, followed by overnight incubation at $37^{\circ} \mathrm{C}$. Tryptic digest was stopped by the addition of trifluoroacetic acid to a final concentration of $10 \%$. Upon tryptic digest, $30 \mu \mathrm{l}$ of tryptic peptides were diluted with 
$20 \mu \mathrm{l}$ of aqueous $0.1 \%$ TFA and $10 \mu \mathrm{l}$ of sample were injected undiluted onto the chromatographic column. Peptide separations were performed using an Ultimate 3000 nano RSLC separation system (Thermo Fisher Scientific, Germering, Germany) coupled to the maXis Impact qToF mass spectrometer equipped with the captive spray electrospray source (Bruker, Bremen, Germany). The captive spray source was modified and a stainless steel needle $(20 \mu \mathrm{m}$ ID x $105 \mathrm{~mm}$; Thermo Fisher Scientific, Vienna, Austria) was used instead of the default silica capillary for sample ionization, at $1.8 \mathrm{kV}$, and the source temperature was set to $150^{\circ} \mathrm{C}$. Samples were loaded onto a C18 trap column (300 $\mu \mathrm{m}$ ID x 5 mm Acclaim PepMap, 5 - $\mu \mathrm{m}$ particle size, $100-\AA$ pore size $)$ using cooled $\left(5^{\circ} \mathrm{C}\right)$ aqueous $0.1 \% \mathrm{TFA}$ at $30 \mu \mathrm{l} / \mathrm{min}$ as a loading mobile phase, and separated on a C18 nano separation column (75 $\mu \mathrm{m}$ ID $\mathrm{x}$ $250 \mathrm{~mm}$ Acclaim PepMap, 3- $\mu \mathrm{m}$ particle size, $100-\AA$ pore size) operated at the flow rate of $300 \mathrm{nl} / \mathrm{min}$. The gradient for nanoHPLC separation of tryptic peptides was generated using the following mobile phases: $5 \%$ acetonitrile (AcN) in $0.1 \%$ aqueous formic acid (FA) and $0.08 \% \mathrm{FA}$ in $50 \% \mathrm{AcN}, 30 \%$ methanol, $10 \%$ trifluoroethanol (TFE), $0.08 \%$ FA.

All masses with a signal higher than 5,000 counts were submitted for fragmentation (MS/MS). MS/MS fragmentation was performed by applying a cycle time of $3 \mathrm{~s}$, single charged peptides were excluded from fragmentation, and active exclusion was used for fragmented masses for $2 \mathrm{~min}$. All MS/MS spectra were transformed into .mgf files for data analysis by applying an internal script from Data Analysis 4.1 (Bruker). Data analysis was performed using Mascot 2.4.1 (Matrix Science, London, UK) embedded in ProteinScape 3.1 (Bruker). Search parameters were as follows: the latest version of the IPI_human decoy database was used, trypsin was selected as the digestion enzyme, and two miscleavages were allowed. Monoisotopic peptide masses were searched with 50-ppm peptide mass tolerance and 0.5-Da fragment mass tolerance. The large mass tolerance for the database search was selected, although the actual mass accuracy of the data analyzed was $<5$ ppm. Carbamidomethyl on Cys was selected as a fixed modification and oxidation on Met as the variable peptide modification. Matches with Mascot scores $>15$, two peptides per protein, and a significance threshold of $p<0.05$ were considered positive hits.

The sample size was planned as 20 patients per group ( $n=40$; false discovery rate 0.05 , power $80 \%$, assumed proportion of true null hypotheses 0.95 , and assumed standardized effect size 1; based on two-sample paired $t$ test) and patients were matched for age ( \pm 5 years). Similarities to tag count-based mRNA technologies led us to employ an overdispersed Poisson model combined with empirical Bayes methods, as commonly used to estimate mRNA tag abundance. Count data were loaded into $\mathrm{R}$ (version 3.1.3) and protein abundance was estimated by calculating peptide counts normalized to counts per million (cpm). Log2-fold change was estimated based on variance stabilized average $\log 2 \mathrm{cpm}$ values using the package edgeR. [18]. Resulting $p$ values were corrected for multiple testing according to Bass [19]. A $q$ value of $<0.25$ was considered statistically significant.

Statistical analysis of demographic data was computed applying independent $t$ test for scaled variables (age, BMI, ICIQ score, number of vaginal deliveries) and Chi-squared test for nominal variables (status of menopause, presence of chronic disease).

The manuscript was structured according to the Strengthening the Reporting of Observational Studies in Epidemiology (STROBE) guidelines (for observational studies) and to the Minimum Information About A Proteomics Experiment (MIAPE) (for proteomic research).

\section{Results}

One urine sample was retrieved from each participant (cases $n=20$; controls $n=20$ ) and included in the final analysis (total $n=40)$. Demographic data were similar in the case and control group (Table 1). We identified 6,415 proteins in the control group and 5,310 in the case group when identifications with one peptide per protein were included and identifications from all samples were taken into account. However, only proteins with at least two detected and identified peptides were selected for further statistical analysis. Thus, 828 individual proteins were entered into the statistical analysis.

Six of the 828 proteins showed a significant difference in abundance in urine samples between SUI and controls ( $q$ value $<0.25$; Table 2). Four proteins showed a higher abundance in SUI samples compared with controls: plasma serine protease inhibitor (logFC 1.11), leucine-rich alpha-2-glycoprotein (logFC 3.91), lysosomal alpha-glucosidase (logFC 1.24), and peptidyl-prolyl cis- trans isomerase A (logFC 1.96). Two proteins (gene symbol: UMOD; gene symbol: KIAA0586) presented a lower abundance in SUI samples compared with controls: uromodulin $(\log \mathrm{FC}-4.87)$ and TALPID3 $(\log \mathrm{FC}-1.99)$.

\section{Discussion}

This pilot study identified six putative SUI-specific urinary proteins, to our knowledge for the first time.

Plasma serine protease inhibitor (SERPINA5), leucine-rich alpha-2-glycoprotein (LRG1), lysosomal alpha-glucosidase (GAA) and peptidyl-prolyl cis-trans isomerase A (PPIA) were more highly expressed in urine samples from women with SUI. Plasma serine protease inhibitor (SERPINA5) is usually present in urine in very low concentrations and serves, among other functions, as a pro-inflammatory factor. Recent publications regarding diverse medical conditions, including pediatric 
Table 1 Demographic data of patients with stress urinary incontinence (SUI) versus controls

\begin{tabular}{llll}
\hline & Patients with SUI $(n=20)$ & Controls $(n=20)$ & $p$ value \\
\hline Age $($ years $)$, mean $( \pm \mathrm{SD})$ & $49( \pm 9)$ & $49( \pm 10)$ & 0.961 \\
BMI $\left(\mathrm{kg} / \mathrm{m}^{2}\right)$, mean $( \pm \mathrm{SD})$ & $28( \pm 6)$ & $25( \pm 5)$ & 0.119 \\
ICIQ sum score, mean $( \pm \mathrm{SD})$ & $13( \pm 4)$ & $0(0)$ & 0.000 \\
Vaginal deliveries, $n$ mean $( \pm \mathrm{SD})$ & $2.1( \pm 0.9)$ & $1.9( \pm 0.7)$ & 0.462 \\
Chronic diseases, $n(\%)^{\mathrm{a}}$ & $10 / 20(50)$ & $11 / 20(55)$ & 0.752 \\
Menopause, $n(\%)$ & & & 0.501 \\
$\quad$ Premenopausal & $15 / 20(75)$ & $8 / 20(60)$ & \\
Postmenopausal & $5 / 20(25)$ & $8 / 20(40)$ & \\
\hline
\end{tabular}

ICIQ-UI short form International Consultation on Incontinence Modular Questionnaire

${ }^{\text {a }}$ Number of patients with chronic diseases (including hypertension, coronary heart disease, colitis, depression, gastritis, diabetes type II, glaucoma, chronic atrial fibrillation, asthma, Hashimoto thyroiditis, hyperthyroidism, tricuspidal valve insufficiency, factor V Leiden) leukemia, breast cancer, HIV infection, and hepatocellular carcinoma have identified the role of SERPINA5 [20-23]. Leucinerich alpha-2-glycoprotein, a secreted protein normally present in plasma, is involved in nonspecific inflammatory and cancer processes. It has recently been described in the context of ulcerative colitis activity, invasive bladder cancer, biliary tract cancer, lung cancer, pancreatic cancer, heart failure, neutrophilic granulocyte differentiation, and autoimmune diseases [24].

Lysosomal alpha-glucosidase (GAA) is a protein essential for the degradation of glycogen to glucose in lysosomes, which is present in all tissue cell types. Mutations in the respective gene result in Pompe disease, a condition in which a lack of lysosomal alpha-glucosidase leads to the intralysosomal accumulation of glycogen, which consequently disables heart and skeletal muscles. The protein has also been identified as a potential biomarker for gut wall integrity in infants with necrotizing enterocolitis, an inflammatory process involving intestinal tissue [25].

Peptidyl-prolyl cis-trans isomerase A is involved in inflammatory processes/immunomodulation and induction of interleukin-6 release from macrophages. Recent publications have discussed an involvement in type II diabetes mellitus, vascular disease, and gastric adenocarcinoma [26].
The proteins uromodulin and TALPID3 had lower expression in SUI samples. Among other functions, uromodulin is involved in the prevention of urinary tract infection, water/ electrolyte balance, and kidney innate immunity, and is usually highly abundant in the urine of healthy humans [27]. TALPID3 is required for ciliogenesis and sonic hedgehog/ SHH signaling [28].

We do not imply to have found biomarkers for SUI, but rather a group of proteins with a significantly different abundance in SUI patients compared with controls. By investigating the known functions, tissue specificities and interactions of the specific proteins, we may be able to gain insight into the potential mechanisms of the pathophysiology and etiology of SUI. Proteins that were identified with significantly higher abundance in SUI samples, are described as being involved in inflammatory processes and cancer development, whereas those with a significantly lower abundance usually seem to have a protective effect in the urinary tract system.

The strengths of this study include that urine samples were retrieved from a population with very strict inclusion and exclusion criteria to avoid confounding factors. Demographic data showed that there was no significant difference between the case and control group regarding BMI, age, and parity (Table 1).
Table 2 Proteins with a significantly different abundance in the urine of patients with SUI compared with controls

\begin{tabular}{|c|c|c|c|c|}
\hline Protein & Accession & Gene symbol & $\operatorname{logFC}$ & $q$ value \\
\hline $\begin{array}{l}\text { Tax_Id=9606 Gene_Symbol=SERPINA5 } \\
\text { plasma serine protease inhibitor }\end{array}$ & IPI00007221 & SERPINA5 & 1.111 & 0.029 \\
\hline $\begin{array}{l}\text { Tax_Id=9606 Gene_Symbol=LRG1 } \\
\text { leucine-rich alpha-2-glycoprotein }\end{array}$ & IPI01012772 & LRG1 & 3.909 & 0.019 \\
\hline $\begin{array}{l}\text { Tax_Id=9606 Gene_Symbol=GAA } \\
\text { lysosomal alpha-glucosidase }\end{array}$ & IPI00293088 & GAA & 1.237 & 0.062 \\
\hline Tax_Id = 9606 Gene_Symbol=UMOD uromodulin & IPI00640271 & UMOD & -4.867 & 0.002 \\
\hline $\begin{array}{l}\text { Tax_Id=9606 Gene_Symbol=PPIA } \\
\text { peptidyl-prolyl cis-trans isomerase A }\end{array}$ & IPI00910407 & PPIA & 1.962 & 0.227 \\
\hline Tax_Id=9606 Gene_Symbol=KIAA0586 TALPID3 & IPI01010584 & KIAA0586 & -1.992 & 0.227 \\
\hline
\end{tabular}

$\log F C$ logarithm of expression 1 (cases) minus the logarithm of expression 2 (controls) to basis 2 (log2(Exp1)$\log 2(\operatorname{Exp} 2)=\log \mathrm{FC})$ 
Urine samples were processed according to a standardized protocol within a very short time frame after collection (maximum $1 \mathrm{~h}$ ). Moreover, all steps of sample processing were consecutively executed by two of the authors, which reduces a potential inter-observer bias and provides consistency in sample handling. Whereas previous studies on SUI have tested serum and/or urinary proteins as potential biomarkers for SUI, there has been no other study, to our knowledge, that has aimed to compare the complete urinary proteome of patients with SUI with that of healthy controls. Preceding studies have targeted specific proteins suspected to play a role in the development of SUI (e.g., serum C-reactive protein, relaxin, estrogen, etc.) [14, 15].

By applying liquid chromatography and mass spectrometry, we were able to possibly identify a significant and sufficient number of proteins present in one urine sample, which provides the ability to avoid a pre-selection of candidate proteins. The main limitation of this study is that we only retrieved and investigated one urine sample per patient. Therefore, we cannot avoid the bias that the urinary proteome potentially changes in one individual dependent on, for example, daytime, food intake, method of retrieval, etc. However, there is no guideline for urine sample collection regarding subsequent proteomic analysis and little is known about circadian urinary proteome changes or external influences.

Another limitation is the incomplete "humane proteome mapping." Despite the efforts of the research community to identify and characterize all human proteins, this project has not yet been completed. Therefore, it is possible to identify proteins that have not yet been characterized, but which are hypothesized as products of specific genes owing to the similarity of their peptide chains to known proteins.

Last, by investigating the urinary proteome only at one time point, we cannot draw a conclusion on whether the significantly differently expressed proteins are a consequence of the pathological process, or whether they themselves are directly involved in causal processes.

The relevance of these results regarding the pathogenesis of SUI, focusing on protein interactions, needs to be more broadly investigated and the results of this pilot study need to be replicated in a different population.

Acknowledgements Open access funding provided by Medical University of Vienna. The authors would like to acknowledge Prof Paul Riss, former Head of Department of Obstetrics and Gynecology, Moedling, Austria, for his consistent disposition as a mentor during the conduction and writing of this work.

\section{Compliance with ethical standards}

Conflicts of interest None.

Financial disclaimer This project was supported by an IUGA 2014 Research Grant (Basic Science).
Funding Research Grant the International Urogynecology Association (2014).

Open Access This article is distributed under the terms of the Creative Commons Attribution 4.0 International License (http:// creativecommons.org/licenses/by/4.0/), which permits unrestricted use, distribution, and reproduction in any medium, provided you give appropriate credit to the original author(s) and the source, provide a link to the Creative Commons license, and indicate if changes were made.

\section{References}

1. Haylen BT, de Ridder D, Freeman RM, Swift SE, Berghmans B, Lee J, Monga A, Petri E, Rizk DE, Sand PK, Schaer GN (2010) An International Urogynecological Association (IUGA)/International Continence Society (ICS) joint report on the terminology for female pelvic floor dysfunction. Int Urogynecol J 21:5-26. doi:10.1007/ s00192-009-0976-9

2. Garely AD, Noor N (2014) Diagnosis and surgical treatment of stress urinary incontinence. Obstet Gynecol 124:1011-1027. doi: 10.1097/AOG.0000000000000514

3. Lawrence JM, Lukacz ES, Nager CW, Hsu JW, Luber KM (2008) Prevalence and co-occurrence of pelvic floor disorders in community-dwelling women. Obstet Gynecol 111:678-685. doi: 10.1097/AOG.0b013e3181660c1b

4. Offermans MP, Du Moulin MF, Hamers JP, Dassen T, Halfens RJ (2009) Prevalence of urinary incontinence and associated risk factors in nursing home residents: a systematic review. Neurourol Urodyn 28:288-294. doi:10.1002/nau.20668

5. Rortveit G, Hannestad YS, Daltveit AK, Hunskaar S (2001) Age- and type-dependent effects of parity on urinary incontinence: the Norwegian EPINCONT study. Obstet Gynecol 98: $1004-1010$

6. Grodstein F, Fretts R, Lifford K, Resnick N, Curhan G (2003) Association of age, race, and obstetric history with urinary symptoms among women in the nurses' health study. Am J Obstet Gynecol 189:428-434

7. Thorp JM Jr, Norton PA, Wall LL, Kuller JA, Eucker B, Wells E (1999) Urinary incontinence in pregnancy and the puerperium: a prospective study. Am J Obstet Gynecol 181:266-273

8. Burgio KL, Zyczynski H, Locher JL, Richter HE, Redden DT, Wright KC (2003) Urinary incontinence in the 12-month postpartum period. Obstet Gynecol 102:1291-1298

9. Subak LL, Richter HE, Hunskaar S (2009) Obesity and urinary incontinence: epidemiology and clinical research update. J Urol 182:S2-S7. doi:10.1016/j.juro.2009.08.071

10. Hannestad YS, Lie RT, Rortveit G, Hunskaar S (2004) Familial risk of urinary incontinence in women: population based cross sectional study. BMJ Br Med J 329:889-891. doi:10.1136/bmj. 329.7471 .889

11. Altman D, Forsman M, Falconer C, Lichtenstein P (2008) Genetic influence on stress urinary incontinence and pelvic organ prolapse. Eur Urol 54:918-922. doi:10.1016/j.eururo.2007.12.004

12. Rohr G, Kragstrup J, Gaist D, Christensen K (2004) Genetic and environmental influences on urinary incontinence: a Danish population-based twin study of middle-aged and elderly women. Acta Obstet Gynecol Scand 83:978-982. doi:10.1111/j.00016349.2004.00635.x

13. Hsiao SM, Lin HH, Kuo HC (2012) The role of serum C-reactive protein in women with lower urinary tract symptoms. Int Urogynecol J 23:935-940. doi:10.1007/s00192-012-1715-1 
14. Harvey MA, Johnston SL, Davies GA (2008) Mid-trimester serum relaxin concentrations and post-partum pelvic floor dysfunction. Acta Obstet Gynecol Scand 87:1315-1321. doi:10.1080/ 00016340802460321

15. Waetjen LE, Johnson WO, Xing G, Feng WY, Greendale GA, Gold EB, Study of Women's Health Across the N (2011) Serum estradiol levels are not associated with urinary incontinence in midlife women transitioning through menopause. Menopause 18:1283-1290. doi:10.1097/gme.0b013e31821f5d25

16. Avery K, Donovan J, Peters TJ, Shaw C, Gotoh M, Abrams P (2004) ICIQ: a brief and robust measure for evaluating the symptoms and impact of urinary incontinence. Neurourol Urodyn 23: 322-330. doi:10.1002/nau.20041

17. Mitulović G, Stingl C, Steinmacher I, Hudecz O, Hutchins JRA, Peters J-M, Mechtler K (2009) Preventing Carryover of Peptides and Proteins in Nano LC-MS Separations. Anal Chem 81:59555960. doi:10.1021/ac900696m

18. Robinson MD, McCarthy DJ, Smyth GK (2010) edgeR: a Bioconductor package for differential expression analysis of digital gene expression data. Bioinformatics 26:139-140. doi:10.1093/ bioinformatics/btp616

19. Bass A (2015) qualue: Q-value estimation for false discovery rate control. 2016 GitHub, Inc. http://github.com/jdstorey/qvalue. Accessed 9 April 2016

20. Haynes BP, Viale G, Galimberti V, Rotmensz N, Gibelli B, Smith IE, Dowsett M (2014) Differences in expression of proliferationassociated genes and RANKL across the menstrual cycle in estrogen receptor-positive primary breast cancer. Breast Cancer Res Treat 148:327-335. doi:10.1007/s10549-014-3181-6

21. Priola GM, Foster MW, Deal AM, Richardson BM, Thompson JW, Blatt J (2015) Cerebrospinal fluid proteomics in children during induction for acute lymphoblastic leukemia: a pilot study. Pediatr Blood Cancer 62:1190-1194. doi:10.1002/pbc.25420
22. Van Raemdonck G, Zegels G, Coen E, Vuylsteke B, Jennes W, Van Ostade X (2014) Increased Serpin A5 levels in the cervicovaginal fluid of HIV-1 exposed seronegatives suggest that a subtle balance between serine proteases and their inhibitors may determine susceptibility to HIV-1 infection. Virology 458-459:11-21. doi:10. 1016/j.virol.2014.04.015

23. Jing Y, Jia D, Wong CM, Oi-Lin Ng I, Zhang Z, Liu L, Wang Q, Zhao F, Li J, Yao M, Wu X, He X (2014) SERPINA5 inhibits tumor cell migration by modulating the fibronectin-integrin betal signaling pathway in hepatocellular carcinoma. Mol Oncol 8:366-377. doi:10.1016/j.molonc.2013.12.003

24. Serada S, Fujimoto M, Ogata A, Terabe F, Hirano T, Iijima H, Shinzaki S, Nishikawa T, Ohkawara T, Iwahori K, Ohguro N, Kishimoto T, Naka T (2010) iTRAQ-based proteomic identification of leucine-rich alpha-2 glycoprotein as a novel inflammatory biomarker in autoimmune diseases. Ann Rheum Dis 69:770-774. doi: 10.1136/ard.2009.118919

25. Benkoe TM, Mechtler TP, Pones M, Prusa AR, KlebermassSchrehof K, Rebhandl W, Kasper DC (2015) The plasma activities of lysosomal enzymes in infants with necrotizing enterocolitis: new promising class of biomarkers? Clin Chim Acta 438:279-283. doi: 10.1016/j.cca.2014.08.043

26. Ramachandran S, Venugopal A, Kutty VR et al (2014) Plasma level of cyclophilin A is increased in patients with type 2 diabetes mellitus and suggests presence of vascular disease. Cardiovasc Diabetol 13:38. doi:10.1186/1475-2840-13-38

27. Scolari F, Izzi C, Ghiggeri GM (2015) Uromodulin: from monogenic to multifactorial diseases. Nephrol Dial Transplant 30:1250 1256. doi:10.1093/ndt/gfu300

28. Kobayashi T, Kim S, Lin YC, Inoue T, Dynlacht BD (2014) The CP110-interacting proteins Talpid3 and Cep290 play overlapping and distinct roles in cilia assembly. J Cell Biol 204:215-229. doi:10. $1083 /$ jcb.201304153 